\title{
Notes on the vocalizations of Golden-bellied Grosbeak (Pheucticus chrysogaster)
}

Peter Boesman

In the following we briefly analyze and compare voice of the two races of Golden-bellied Grosbeak (Pheucticus chrysogaster). We also try to quantify the extent of any vocal differences using the criteria proposed by Tobias et al. (2010), as a support for taxonomic review. We have made use of sound recordings available on-line from Xeno Canto (XC) and Macaulay Library (ML).

An overview of voice of both races, illustrated with sonograms:

laubmanni

Song

Venezuela

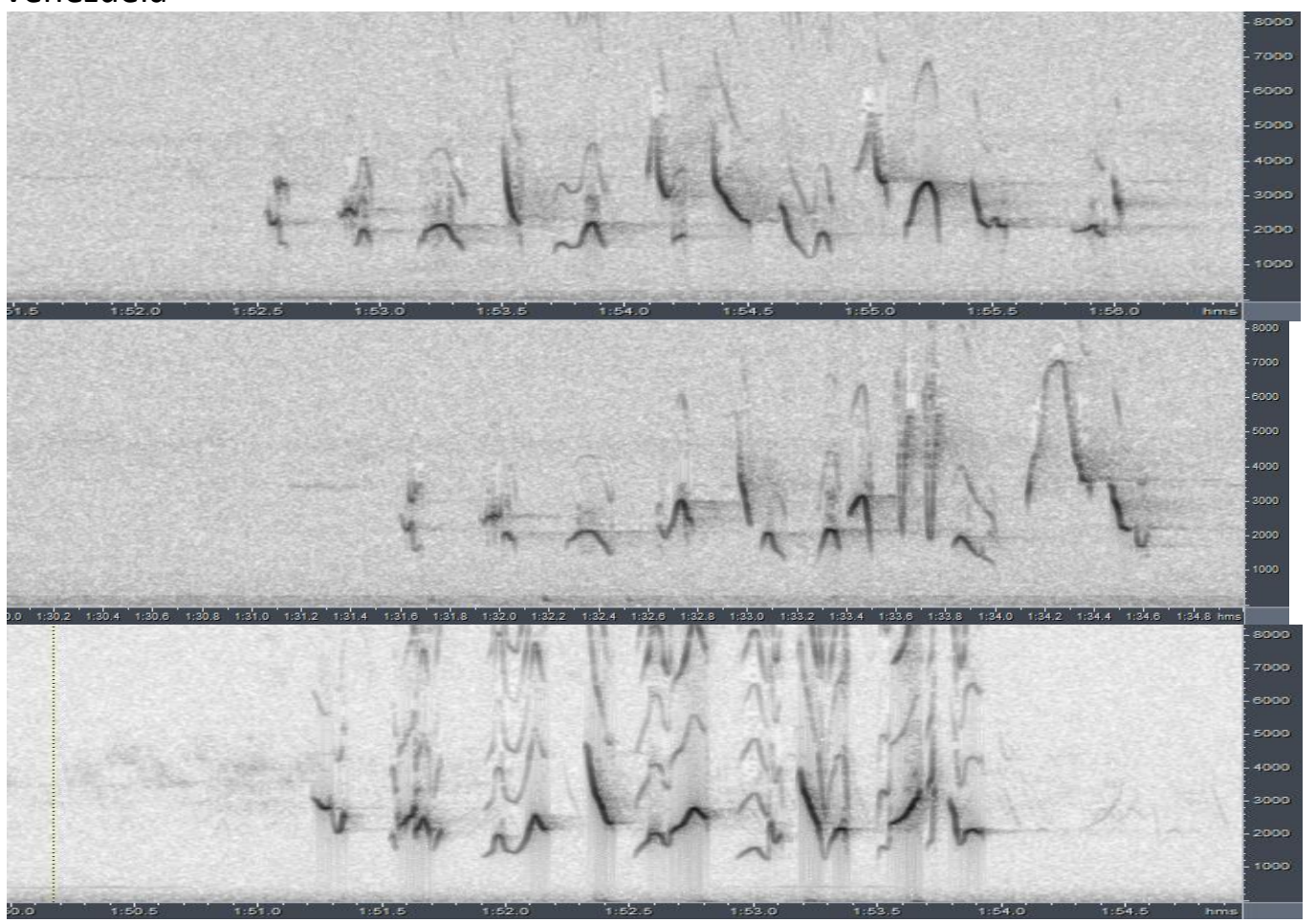

Santa Marta

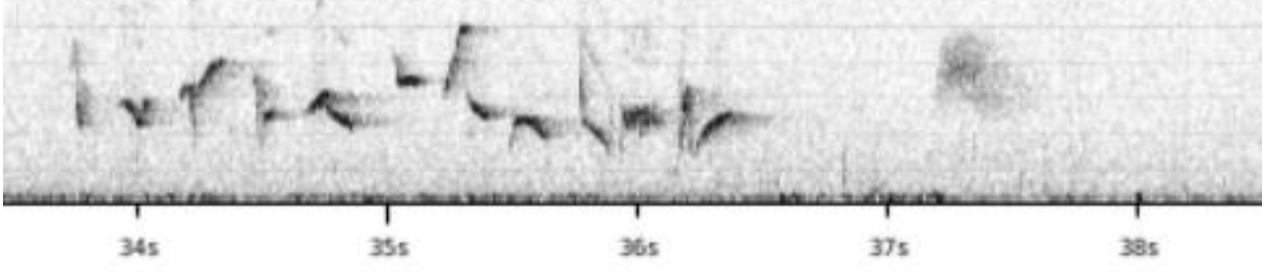


HANDBOOK OF THE

BIRDS PF, THE WORLD

ORNITHOLOGICAL NOTES

Alive
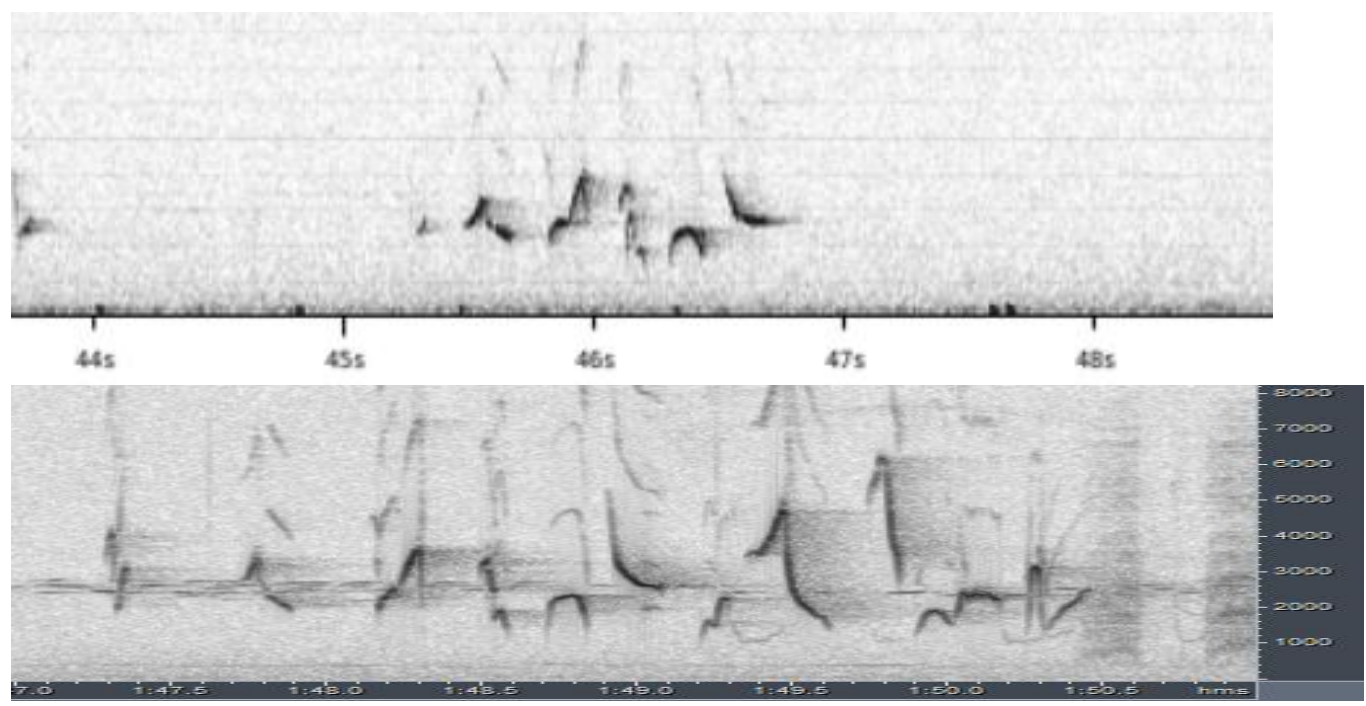

Calls
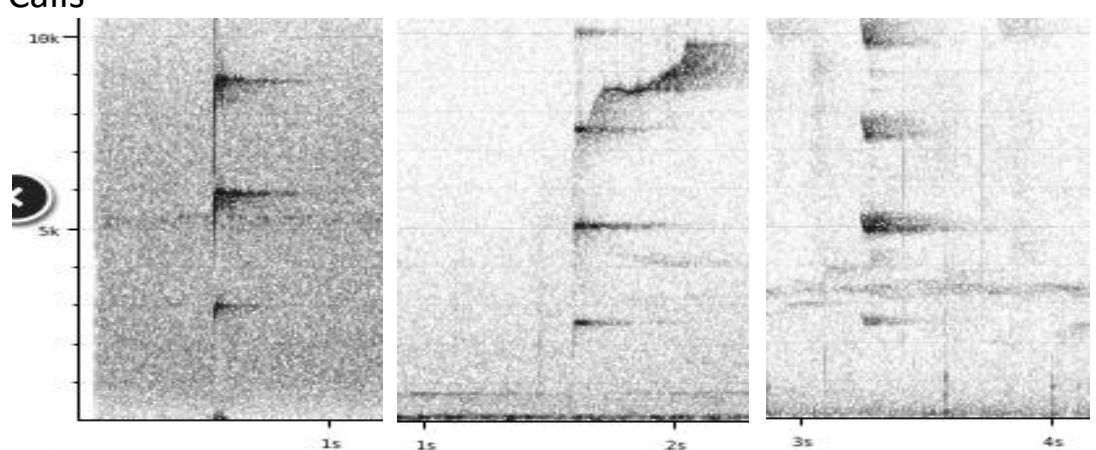

Nominate

Song

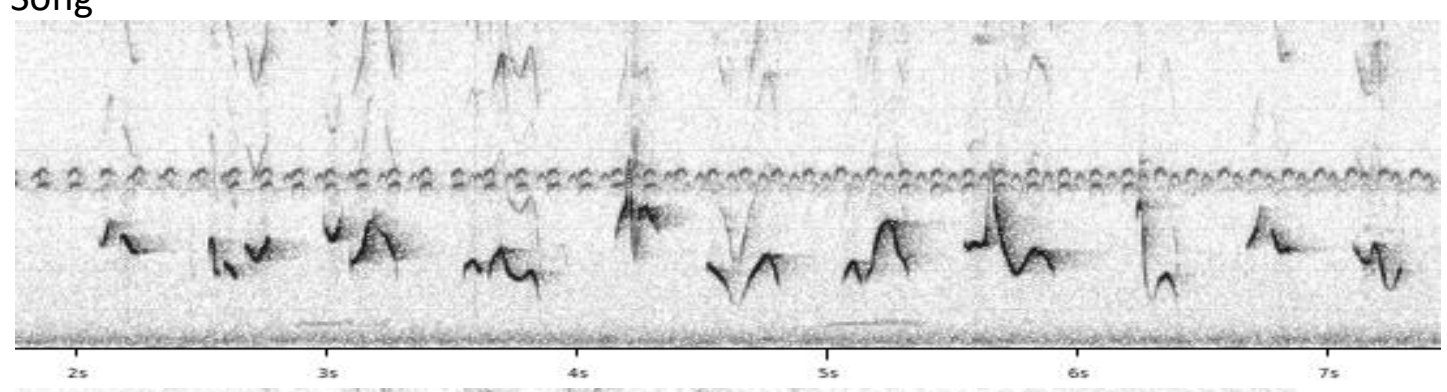

$n^{3}$

In iv an in

2 
HANDBOOK OF THE

AIRD Al ye WORLD ORNITHOLOGICAL NOTES
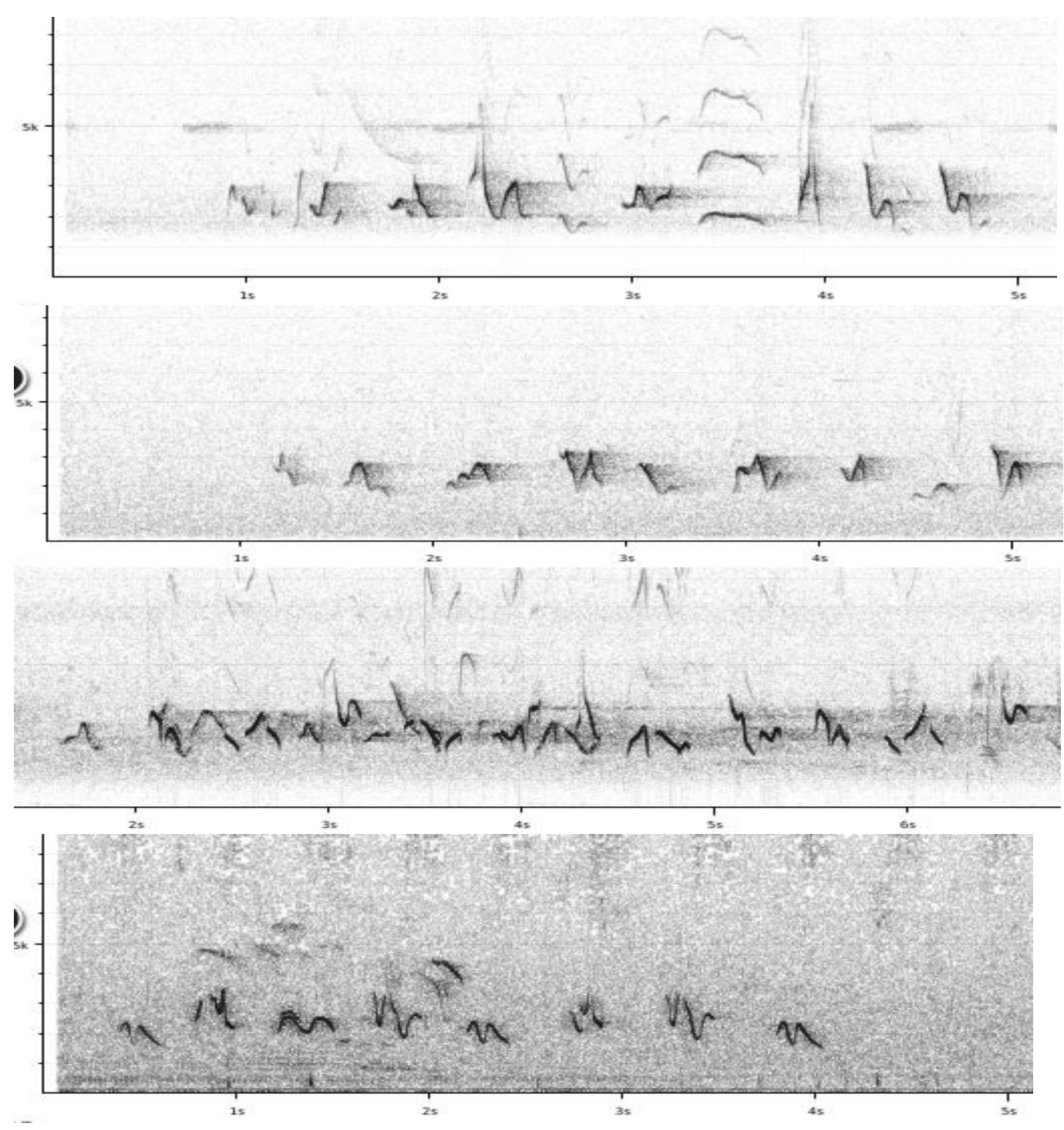

Calls

Ecuador
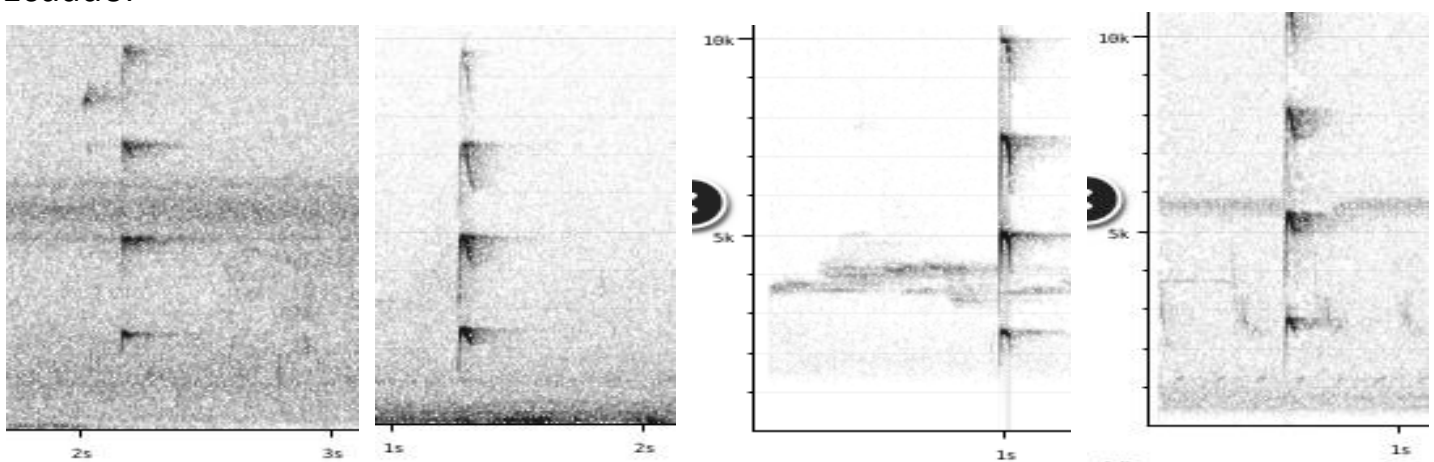

3 

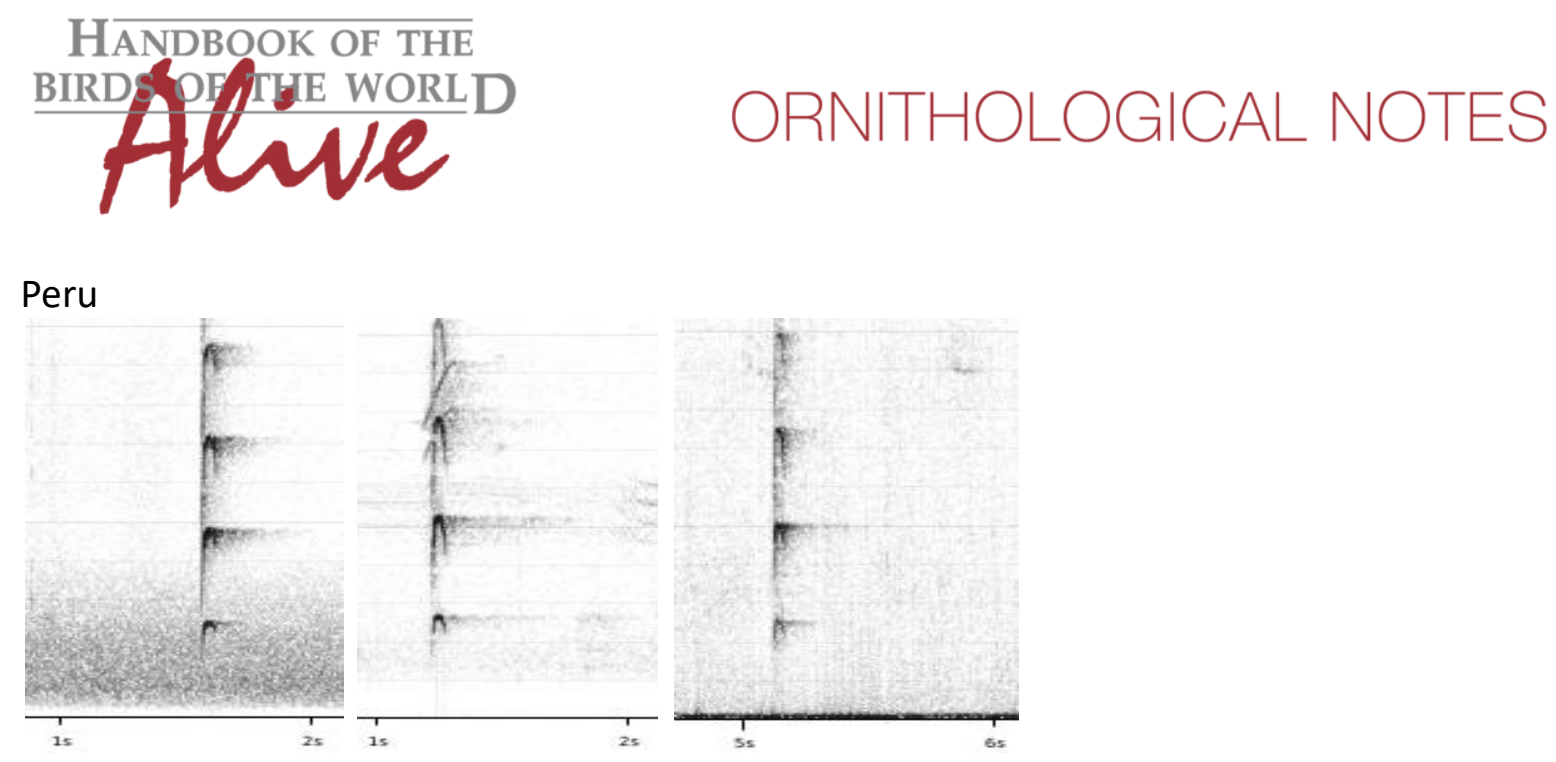

alarm call

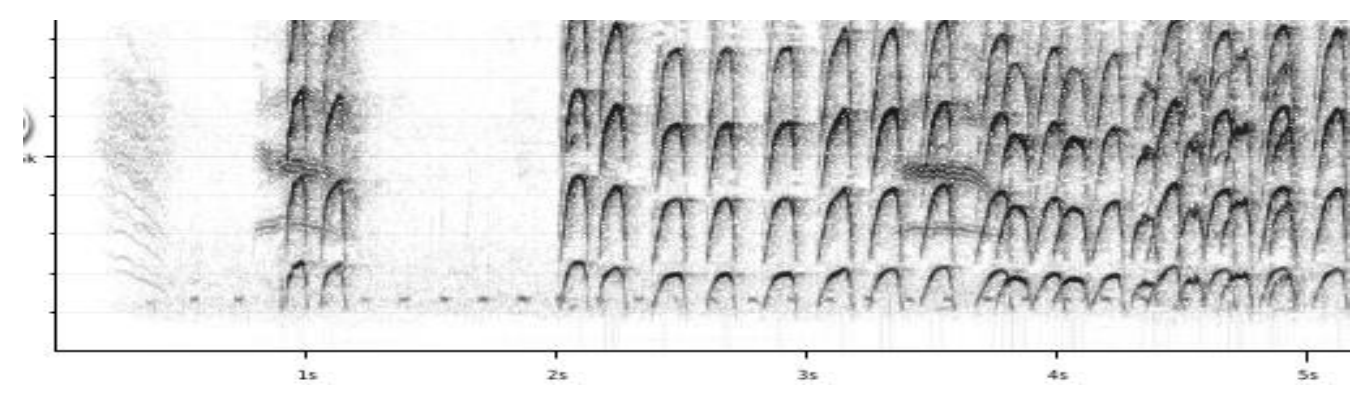

Vocal differences between both races seem to be rather small.

On average, laubmanni has more simple-shaped notes in every song phrase, e.g. simple downslurred or overslurred note shapes (c. 10-50\% of notes) while nominate typically lacks such notes, but some song phrases are indistinguishable (score 1-2).

The short 'pik!' call is about the same in both races (possibly slightly higher-pitched on average in laubmanni ??). Several other calls have been recorded for nominate, but there are apparently no recordings of equivalent homologous calls for laubmanni.

Vocal differences between both races are thus minor, leading to a total vocal score of 1-2.

This note was finalized on 29th June 2016, using sound recordings available on-line at that moment. We would like to thank in particular the many sound recordists who placed their recordings for this species on XC and $\mathrm{ML}$.

\section{References}

Tobias, J.A., Seddon, N., Spottiswoode, C.N., Pilgrim, J.D., Fishpool, L.D.C. \& Collar, N.J. (2010). Quantitative criteria for species delimitation. Ibis 152(4): 724-746.

\section{Recommended citation}

Boesman, P. (2016). Notes on the vocalizations of Golden-bellied Grosbeak (Pheucticus chrysogaster). HBW Alive Ornithological Note 382. In: Handbook of the Birds of the World Alive. Lynx Edicions, Barcelona. (retrieved from http://www.hbw.com/node/1252939 on 30 November 2016). 